\title{
Cardiovascular effects of dapagliflozin in patients with type 2 diabetes and different risk categories: a meta-analysis
}

\author{
Christian Sonesson*, Peter A. Johansson, Eva Johnsson and Ingrid Gause-Nilsson
}

\begin{abstract}
Background: A pre-specified meta-analysis of cardiovascular (CV) events from 21 phase $2 \mathrm{~b} / 3$ dapagliflozin clinical trials was undertaken to characterise the CV profile of dapagliflozin. This showed no increase in CV risk with dapagliflozin compared with control (placebo or comparator treatment) with or without background glucose-lowering therapies. The analysis reported here aimed to characterise the CV profile of dapagliflozin in subgroups of patients in these 21 studies grouped by degree of CV risk, based on both baseline and in-study risk factors (including hypoglycaemic events), with a focus on major adverse CV events (MACE).
\end{abstract}

Methods: Patients with type 2 diabetes, both overall and with different levels of CV risk, including CV disease (CVD) history, age and other CV risk factors, were analysed. A further analysis compared CV risk in patients who experienced a hypoglycaemic event prior to MACE and those who did not. Analyses were based on time to first event using a Cox proportional hazards model stratified by study comparing dapagliflozin versus control.

Results: In total, 9339 patients were included in this meta-analysis; 5936 patients received dapagliflozin 2.5-10 mg (6668 patient-years) and 3403 received control (3882 patient-years). Dapagliflozin is not associated with increased CV risk and results further suggest the potential for a beneficial effect both in the overall population [Hazard Ratio (HR) $0.77 ; 95 \% \mathrm{Cl}(0.54,1.10)$ for MACE] and in those with a history of CVD [HR $0.80(0.53,1.22)]$. These findings were consistent in patients with varying degrees of CV risk, including age, number and type of CVD events in medical history and number of $\mathrm{CV}$ risk factors present. Furthermore, there was no increased risk of MACE in patients who experienced a hypoglycaemic event compared with those who did not.

Conclusions: There was no suggestion of increased risk for MACE with dapagliflozin compared with control in any of the populations investigated. In addition, the results suggest the potential for a beneficial CV effect which is consistent with the multifactorial benefits on CV risk factors associated with sodium-glucose cotransporter-2 (SGLT2) inhibitors.

Keywords: SGLT2 inhibitors, Cardiovascular, Type 2 diabetes, Dapagliflozin, Cardiovascular risk, Major adverse cardiovascular events, Meta-analysis

\section{Background}

In patients with type 2 diabetes mellitus (T2DM), cardiovascular disease (CVD) remains the leading cause of morbidity and mortality, with these individuals at approximately twice the risk of CVD compared with

*Correspondence: Christian.Sonesson@astrazeneca.com

AstraZeneca Gothenburg, Pepparedsleden 1, SE-431 83 Mölndal, Sweden people without diabetes [1, 2]. Although rates have declined, a large burden still remains [3].

The link between improved glycaemic control and an improvement in microvascular outcomes is well established; however, although epidemiological evidence suggests a link [4-6], the effect on CVD risk is less clear [7-11]. In addition, the potential harm associated with severe hypoglycaemia might counterbalance the potential benefit of intensive glucose lowering treatment [12]. The 
need for personalised treatment of hyperglycaemia has been advocated [13-15] and a multifactorial approach to the treatment of risk factors is needed to decrease the cardiovascular (CV) risk [16, 17].

Dapagliflozin is a selective sodium-glucose cotransporter-2 (SGLT2) inhibitor that lowers blood glucose levels by reducing glucose reabsorption in the kidney independently of insulin secretion or action, resulting in increased urinary glucose excretion with associated osmotic diuresis and caloric loss [18]. The efficacy and safety of dapagliflozin has been studied in a wide range of populations as monotherapy or in combination with a variety of other glucose-lowering therapies [19-38]. The mechanism of action of dapagliflozin influences a number of CVD risk factors, in particular, decreasing blood pressure, reducing body weight (predominantly through reductions in total body fat mass, including visceral adipose tissue), reducing waist circumference, and lowering albuminuria and serum uric acid levels, with a low intrinsic risk of hypoglycaemia $[26,39,40]$.

The US Food and Drug Administration (FDA) and European Medicines Agency (EMA) have issued guidance requiring that new diabetes therapies should rule out an unacceptable increase in CVD risk [41, 42]. Since then, a number of large CV outcome studies to clarify the effects of new classes of glucose-lowering therapies have either been conducted [43-47] or are ongoing [48-50]. Positive CV outcomes data, including a beneficial effect on hospitalisation for heart failure, were recently published for the SGLT2 inhibitor empagliflozin, which has a similar profile to dapagliflozin, showing the benefits of improving multiple CV risk factors with SGLT2 inhibitors [47]. Additionally, the ongoing large CV outcome trial DECLARE TIMI-58 [48] is being conducted in a broad population of patients with either established CVD or multiple CV risk factors and will aim to evaluate the effects of dapagliflozin on CV outcomes, with an estimated completion date of 2019.

In a pre-specified meta-analysis investigating $\mathrm{CV}$ outcomes in 21 trials from the dapagliflozin clinical development programme, which was conducted in line with the FDA guidance, no increase in CVD risk was observed in patients with T2DM receiving dapagliflozin compared with those receiving control (placebo or comparator treatment) with or without background glucose-lowering therapies [51]. The CV risk increases in patients with age, decrease in renal function and presence of one or several risk factors or comorbid conditions. The metaanalysis reported here aimed to characterise the CV profile of dapagliflozin overall and in subgroups of patients grouped by degree of $\mathrm{CV}$ risk, based both on baseline and in-study risk factors (i.e. hypoglycaemic events), with a focus on major adverse $\mathrm{CV}$ events (MACE).

\section{Methods}

\section{Patient population}

Data from Phase 2b studies of 12-24 weeks' duration (five studies), and all Phase 3 studies of up to 208 weeks' duration (16 studies) from the dapagliflozin clinical development programme in patients with T2DM, with the exception of an open-label Japanese study, were included (Additional file 1: Table S1). These studies compared dapagliflozin 2.5-10 mg with control (placebo or comparator treatment) as monotherapy or in combination with other glucose-lowering therapies, including metformin, sulfonylureas, thiazolidinediones, insulin and dipeptidyl peptidase 4 inhibitors. Methods for each individual study have previously been published [19-38]. All clinical study protocols were approved by the relevant institutional review boards/ethics committees and all enrolled patients provided written informed consent.

Analyses of $\mathrm{CV}$ outcomes were performed in several populations:

- In the overall population, comparison of CV outcomes according to the number of $\mathrm{CV}$ risk factors present in addition to T2DM. Cardiovascular risk factors included: age $>65$ years, history of CVD, history of hypertension, history of dyslipidaemia, smoking history, first degree family members with a history of premature coronary heart disease, and baseline estimated glomerular filtration rate (eGFR) $<60 \mathrm{~mL} / \mathrm{min} / 1.73 \mathrm{~m}^{2}$.

- In a subpopulation with a history of CVD:

- Comparison of CV outcomes according to the types of previous CVD events experienced and the number of different CVD event types in a patient's history. The types of previous CVD events were defined as: coronary artery disease (myocardial infarction [MI], hospitalisation for unstable angina [UA], coronary artery bypass graft, percutaneous coronary intervention or stable angina), cerebrovascular disease (carotid artery disease, carotid endarterectomy or stenting, stroke or transient ischaemic attack), peripheral vascular disease (amputation, peripheral vascular disease or peripheral vascular surgery) or congestive heart failure (CHF).

- In a subpopulation of elderly patients aged $\geq 65$ years with a history of both CVD and hypertension.

- Comparison of patients with or without hypoglycaemia prior to MACE in both the overall population and the subpopulation of patients with a history of CVD.

\section{Cardiovascular outcomes}

Cardiovascular safety events were identified through an independent, blinded adjudication process, with 
standardised MedDRA (Medical Dictionary for Regulatory Activities) queries used to select the events for adjudication. In line with the FDA Guidance, the primary CVD event of interest in this meta-analysis was the composite of CVD death, MI, stroke and hospitalisation for UA (MACE plus UA) although we focus on MACE (composite of CVD death, MI and stroke) for the majority of the analyses here. Other CVD events investigated were the individual events of $\mathrm{CV}$ death, MI, stroke, hospitalisation for UA, unplanned coronary revascularisation, and hospitalisation for heart failure.

\section{Analysis methods}

Analyses were based on time to first event using a Cox proportional hazards model stratified by study and including a term defining the treatment received by individual patients across the pooled studies (either dapagliflozin or control). Results were supported by Mantel-Haenszel methods (asymptotic and exact). Only studies with at least one adjudicated event contributed to the respective analyses. Any imbalances in CVD risk factors due to an unequal randomisation ratio were adjusted for in the analyses through stratification by study in the model. Hazard ratios (HRs) and $95 \%$ confidence intervals (CIs) comparing dapagliflozin with control were calculated. An estimated $\mathrm{HR}<1$ indicates a favourable effect of dapagliflozin versus control. Kaplan-Meier estimates for cumulative incidence were calculated for MACE + UA, MACE, their individual components (CV death, MI, stroke and UA) and hospitalisation for heart failure.

\section{Results}

\section{Patients}

Overall there were 9339 patients included in this metaanalysis, with 10,550 patient-years of exposure to study drug; 5936 patients received dapagliflozin (6668 patientyears) and 3403 received control (3882 patient-years). There were 3214 patients with a history of CVD (1856 and 1358 treated with dapagliflozin and control, respectively); the subgroup of elderly patients ( $\geq 65$ years) with a history of CVD and hypertension included 1263 patients from 19 studies (707 patients treated with dapagliflozin and 556 with control). Patient demographics and baseline characteristics were balanced between dapagliflozin and control groups within each studied population (Table 1). Patients with history of CVD, and elderly patients with history of CVD and hypertension, were older, had a longer T2DM duration, more impaired renal function, lower low-density lipoprotein (LDL)-cholesterol and higher mean systolic blood pressure, compared with patients in the overall population. In the overall population, a slight imbalance in history of CVD, hypertension and CHF between dapagliflozin and control groups was observed and this was accounted for in the analysis.

\section{Cardiovascular outcomes in the overall population}

A total of 176 MACE plus UA events were observed in the overall population; 95 events in patients receiving dapagliflozin and 81 events in patients receiving control [HR 0.787; 95 \% CI $(0.579,1.070)$ ] (Fig. 1). A total of 134 MACE events (72 events in patients receiving dapagliflozin and 62 events in patients receiving control) were observed in the overall population [HR 0.772; 95 \% CI $(0.543,1.097)$ ] (Fig. 1). The cumulative probability of MACE + UA and MACE both showed a gradual separation of the dapagliflozin and control curves during the treatment period (Fig. 2). There was a consistent pattern, with beneficial or neutral point estimates for all individual types of $\mathrm{CV}$ events in dapagliflozin- compared with control-treated patients (Fig. 3), including a beneficial estimate on hospitalisation for heart failure [HR 0.361; $95 \%$ CI $(0.156,0.838)$ ] (Fig. 3), which showed an early separation of the cumulative probability of an event between the treatment groups (Fig. 2); albeit only based on 26 events. For all Kaplan-Meier plots in Fig. 2, the relatively few events occurring in the later time period should be noted. The presence or absence of specific CVD risk factors (including family history of premature coronary heart disease, baseline eGFR, dyslipidaemia, hypertension, smoking, history of CVD and older age), did not generally affect the estimated HRs, which were less than 1 in all subgroups analysed (Fig. 4). When patients were considered according to the present number of CVD risk factors, estimated HRs were less than 1 for all categories ( $\geq 1, \geq 2, \geq 3, \geq 4, \geq 5$ or $\geq 6$ risk factors) with a tendency towards higher event rates with increasing number of risk factors in both the dapagliflozin and the control groups (Fig. 5).

\section{Cardiovascular outcomes in patients with a history of CVD}

A total of 128 MACE plus UA events were observed in the subgroup of patients with a history of CVD; 67 events in patients receiving dapagliflozin and 61 events in patients receiving control [HR 0.806; $95 \%$ CI $(0.562$, 1.156)] (Fig. 1). A total of 95 MACE events were observed in this subgroup; 50 in patients receiving dapagliflozin and 45 in patients receiving control [HR 0.802; $95 \% \mathrm{CI}$ $(0.527,1.221)]$ (Fig. 1). The risk for MACE events with dapagliflozin compared with control in patients without a history of CVD also favoured dapagliflozin [HR 0.646; $95 \%(0.336,1.241)]$ (Fig. 4). The pattern of beneficial or neutral point estimates for all individual types of $\mathrm{CV}$ events in dapagliflozin- compared with control-treated patients and a beneficial point estimate for dapagliflozin 
Table 1 Demographics and baseline characteristics

\begin{tabular}{|c|c|c|c|c|c|c|}
\hline & \multicolumn{2}{|l|}{ All patients } & \multicolumn{2}{|c|}{ Patients with history of CVD } & \multicolumn{2}{|c|}{$\begin{array}{l}\text { Elderly patients with hyper- } \\
\text { tension and a history of CVD }\end{array}$} \\
\hline & $\begin{array}{l}\text { DAPA } \\
(\mathrm{N}=5936)\end{array}$ & $\begin{array}{l}\text { CTRL } \\
(\mathrm{N}=3403)\end{array}$ & $\begin{array}{l}\text { DAPA } \\
(n=1856)\end{array}$ & $\begin{array}{l}\text { CTRL } \\
(n=1358)\end{array}$ & $\begin{array}{l}\text { DAPA } \\
\left(\mathrm{n}=707^{\mathrm{a}}\right)\end{array}$ & $\begin{array}{l}\text { CTRL } \\
(n=556)\end{array}$ \\
\hline Age, mean (SD), years & $56.9(10.4)$ & $58.1(10.3)$ & 62.4 & 62.9 & $70.2(4.1)$ & $70.1(4.2)$ \\
\hline$\geq 65$ years $(\%)$ & 24.0 & 28.8 & 40.9 & 43.1 & 100 & 100 \\
\hline \multicolumn{7}{|l|}{ Race } \\
\hline White, n (\%) & 4505 (75.9) & $2644(77.7)$ & $1634(88.0)$ & $1199(88.3)$ & $634(89.7)$ & $521(93.7)$ \\
\hline Other ${ }^{b}, \mathrm{n}(\%)$ & $1431(24.1)$ & $759(22.3)$ & $222(12.0)$ & $159(11.7)$ & $73(10.3)$ & $35(6.3)$ \\
\hline $\mathrm{BMl}$, mean (SD), kg/m² & $31.3(5.7)$ & $31.6(5.8)$ & $32.4(5.4)$ & $32.5(5.9)$ & $31.8(5.0)$ & $32.1(5.4)$ \\
\hline T2DM duration, mean (SD), years & $7.0(7.5)$ & $7.6(7.7)^{c}$ & $11.1(8.4)$ & $11.2(8.3)$ & $13.4(9.3)$ & $13.0(9.1)$ \\
\hline History of CVD (\%) & 31.3 & 39.9 & 100 & 100 & 100 & 100 \\
\hline History of hypertension (\%) & 65.7 & 71.9 & 89.8 & 92.8 & 100 & 100 \\
\hline History of CHF (\%) & 3.9 & 4.8 & 12.6 & 12.0 & 15.4 & 15.3 \\
\hline Smoking history (\%) & 43.3 & 46.3 & 53.3 & 56.4 & 51.8 & 53.1 \\
\hline eGFR, mean (SD), mL/min/1.73 $\mathrm{m}^{2}$ & $83.9(21.3)$ & $83.6(21.1)^{d}$ & $75.7(19.5)$ & $77.0(19.5)^{e}$ & $69.9(18.5)$ & $71.7(17.9)$ \\
\hline $\mathrm{LDL}$, mean (SD), mmol/L & $2.78(0.98)^{f}$ & $2.66(0.96)^{9}$ & $2.47(0.98)^{h}$ & $2.36(0.92)^{i}$ & $2.32(0.90)^{j}$ & $2.28(0.89)^{k}$ \\
\hline SBP, mean (SD), mmHg & $130.4(15.7)^{1}$ & $131.1(14.9)^{\mathrm{m}}$ & $134.5(15.4)^{n}$ & $133.7(14.5)^{\circ}$ & $136.7(15.7)^{\mathrm{p}}$ & $135.6(14.0)^{\mathrm{q}}$ \\
\hline $\mathrm{DBP}$, mean (SD), mmHg & $78.8(9.1)^{\prime}$ & $78.8(8.9)^{\mathrm{m}}$ & $78.0(9.3)^{\mathrm{n}}$ & $77.7(9.1)^{\circ}$ & $76.1(9.3)^{\mathrm{p}}$ & $76.1(9.0)^{q}$ \\
\hline \multicolumn{7}{|l|}{ Concomitant medications of interest: } \\
\hline Any antihypertensive & $3217(54.2)$ & $2061(60.6)$ & $1440(86.4)$ & $1085(86.1)$ & $604(85.4)$ & $476(85.6)$ \\
\hline Diuretics & $1509(25.4)$ & $960(28.2)$ & $788(47.3)$ & $604(47.9)$ & $363(51.3)$ & $282(50.7)$ \\
\hline$\beta$-blockers & $1604(27.0)$ & $1127(33.1)$ & $1045(62.7)$ & $819(65.0)$ & $454(64.2)$ & $367(66.0)$ \\
\hline ACEi/ARBs & $2938(49.5)$ & $1908(56.1)$ & $1327(79.7)$ & $1022(81.1)$ & $556(78.6)$ & $451(81.1)$ \\
\hline Calcium channel blockers & $1126(19.0)$ & $717(21.1)$ & $545(32.7)$ & $431(34.2)$ & $251(35.5)$ & $203(36.5)$ \\
\hline Statins & $2276(38.3)$ & $1582(46.5)$ & $1145(68.7)$ & $928(73.7)$ & $497(70.3)$ & $408(73.4)$ \\
\hline Aspirin & $1906(32.1)$ & $1322(38.8)$ & $1068(64.1)$ & $858(68.1)$ & $456(64.5)$ & $378(68.0)$ \\
\hline
\end{tabular}

ACEi angiotensin converting enzyme inhibitors, $A R B S$ angiotensin receptor blockers, $B M I$ body mass index, CHF congestive heart failure, CTRL control, CVD cardiovascular disease, DAPA dapagliflozin, DBP diastolic blood pressure, eGFR estimated glomerular filtration rate, $L D L$ low density lipoprotein cholesterol, $S D$ standard deviation, SBP systolic blood pressure

a Two patients were not randomised to dapagliflozin, but were subsequently treated with dapagliflozin; ${ }^{\mathrm{b}}$ Other includes Black or African American, Asian and Other; ${ }^{\mathrm{c}} \mathrm{n}=3400 ;{ }^{\mathrm{d}} \mathrm{n}=3402 ;{ }^{\mathrm{e}} \mathrm{n}=1357 ;{ }^{\mathrm{f}} \mathrm{n}=5742 ;{ }^{\mathrm{g}} \mathrm{n}=3234 ;{ }^{\mathrm{h}} \mathrm{n}=1821 ;^{\mathrm{i}} \mathrm{n}=1316{ }^{\mathrm{j}} \mathrm{n}=698 ;{ }^{\mathrm{k}} \mathrm{n}=543{ }^{\mathrm{l}} \mathrm{n}=5619 ;{ }^{\mathrm{m}} \mathrm{n}=3274 ;{ }^{\mathrm{n}} \mathrm{n}=1824 ;{ }^{\circ} \mathrm{n}=1345 ;{ }^{\mathrm{p}} \mathrm{n}=704 ;$ ${ }^{\mathrm{q}} \mathrm{n}=553$

versus control for hospitalisation for heart failure, was also seen in this population (Fig. 3). This was also true for MI, where similar results were observed in the overall population and patients with a history of CVD, albeit with fewer events in the latter population.

When patients were considered according to types of CVD history (Fig. 6a) or number of distinct CVD types experienced in their history (according to the same classes; Fig. 6b), there was no increase in risk for MACE in patients treated with dapagliflozin compared with those treated with control.

\section{Cardiovascular outcomes in elderly patients with a history of CVD and hypertension}

In the subgroup of elderly patients aged at least 65 years who had a history of CVD and hypertension, a total of 65 MACE plus UA events were observed (33 in patients receiving dapagliflozin and 32 in patients receiving control) [HR 0.824; 95 \% CI $(0.497,1.365)$ ] (Fig. 1), and a total of 49 MACE events were observed (26 in patients receiving dapagliflozin and 23 in patients receiving control) [HR 0.916; 95 \% CI $(0.512,1.640)]$. There was no increase in risk for any of the individual components of MACE in dapagliflozin-treated patients compared with those receiving control, although the number of events was low for each individual endpoint (Fig. 3).

\section{Cardiovascular outcomes in patients with or without hypoglycaemia prior to MACE}

No increased risk for MACE was observed with dapagliflozin compared with control in patients who did or did not experience a hypoglycaemic event prior to a first MACE event. This was consistently observed in both the overall population and the subpopulation of patients 


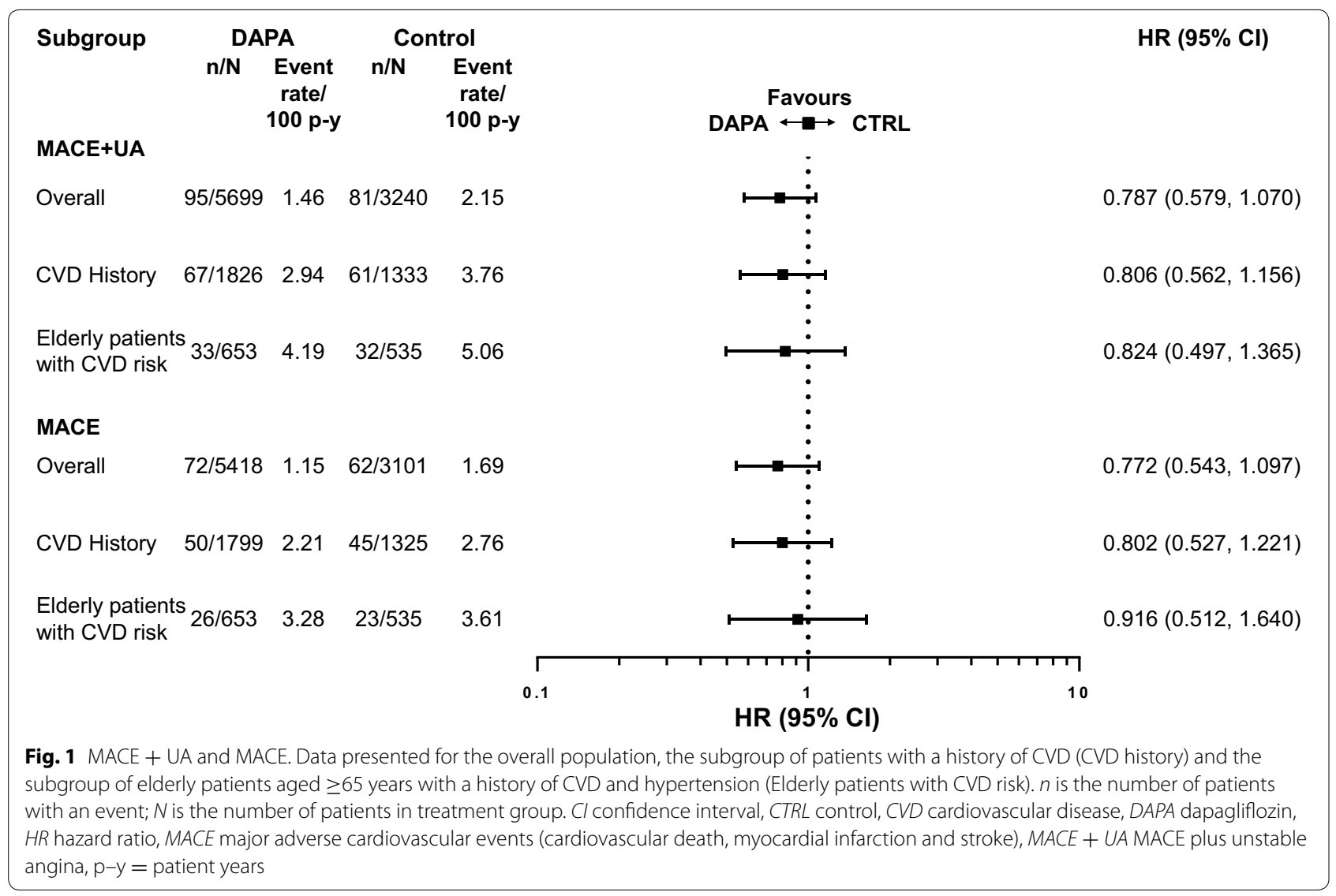

with a history of CVD (Fig. 7). The MACE event rates observed were not consistently higher in patients with a hypoglycaemic event, rather the opposite, although the comparison is hampered by both types of events being post-randomisation events.

\section{Discussion}

To carefully characterise the properties of dapagliflozin, the meta-analysis described here included a broad population of patients with a particular focus on those with an elevated risk for $\mathrm{CV}$ events, using different subpopulations of varying risk. The point estimates of the HRs for MACE and MACE plus UA were similar and in favour of dapagliflozin in the overall population as well as for the sub-populations with higher CV risk. Glycaemic variability and episodes of severe hypoglycaemia have been suggested as predictors of adverse $\mathrm{CV}$ outcomes in patients with T2DM [7, 52-58]. Dapagliflozin reduces hyperglycaemia independently of insulin secretion or action, and as such, has a low intrinsic propensity for hypoglycaemia. In our analysis there was no increased risk for MACE in patients treated with dapagliflozin who did or did not experience a hypoglycaemic event prior to the first MACE event, although the number of events was small.
The results reported here are consistent with previously published meta-analyses of the effect of SGLT2 inhibitors on $\mathrm{CV}$ events. One analysis included pooled data from clinical trials of several members of the SGLT2 inhibitor class, evaluating MACE plus UA in 17,180 patients from 25 studies (14 dapagliflozin, one empagliflozin and 10 canagliflozin studies) [59]. This analysis found no evidence for increased $\mathrm{CV}$ risk, with the HR point estimate in favour of the SGLT2 inhibitor [HR 0.89; $95 \%$ CI $(0.70$, 1.14)] [59]. Meta-analysis provides a method for aggregating and interpreting data from multiple sources and is, therefore, an important tool for examining rare $\mathrm{CV}$ events that occur in diabetes clinical trials [60]. Although $\mathrm{CV}$ events here were prospectively adjudicated by an independent committee, one should note the limitations in the heterogeneous nature of the study populations, the post hoc nature of some of the analyses, the relatively low numbers of events and that data are not generated in a prospectively designed CV outcomes trial.

In addition to reducing hyperglycaemia in T2DM, dapagliflozin may improve glycaemic control in patients with T1DM [61]. Furthermore, dapagliflozin is known to have beneficial effects on several important $\mathrm{CV}$ risk factors, and two recent studies in patients with inadequately controlled 


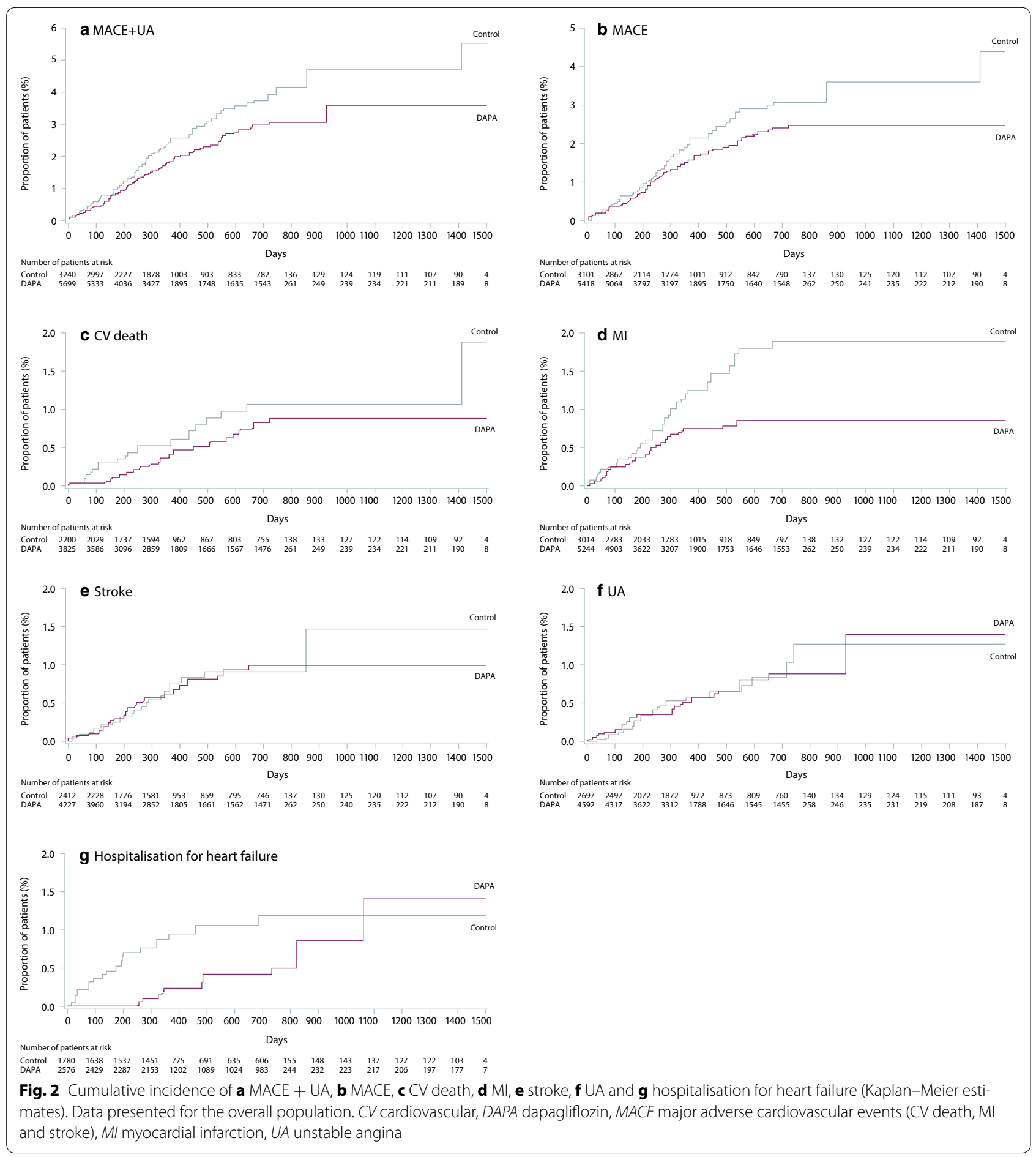

hypertension and T2DM have reported clinically meaningful improvements in blood pressure, body weight, and serum uric acid levels with dapagliflozin [62, 63]. Dapagliflozin is also associated with beneficial effects on albuminuria [64, 65]; collectively suggesting a favourable CV profile. It has also been postulated that the mechanisms underlying the CV benefits of SGLT2 inhibitors could be even more multidimensional and may involve changes in arterial stiffness, cardiac oxygen demand, oxidative stress as well as other potential effects on the sympathetic nervous system, ventricular function and remodelling that remain to be elucidated [40]. Indeed, a murine model 


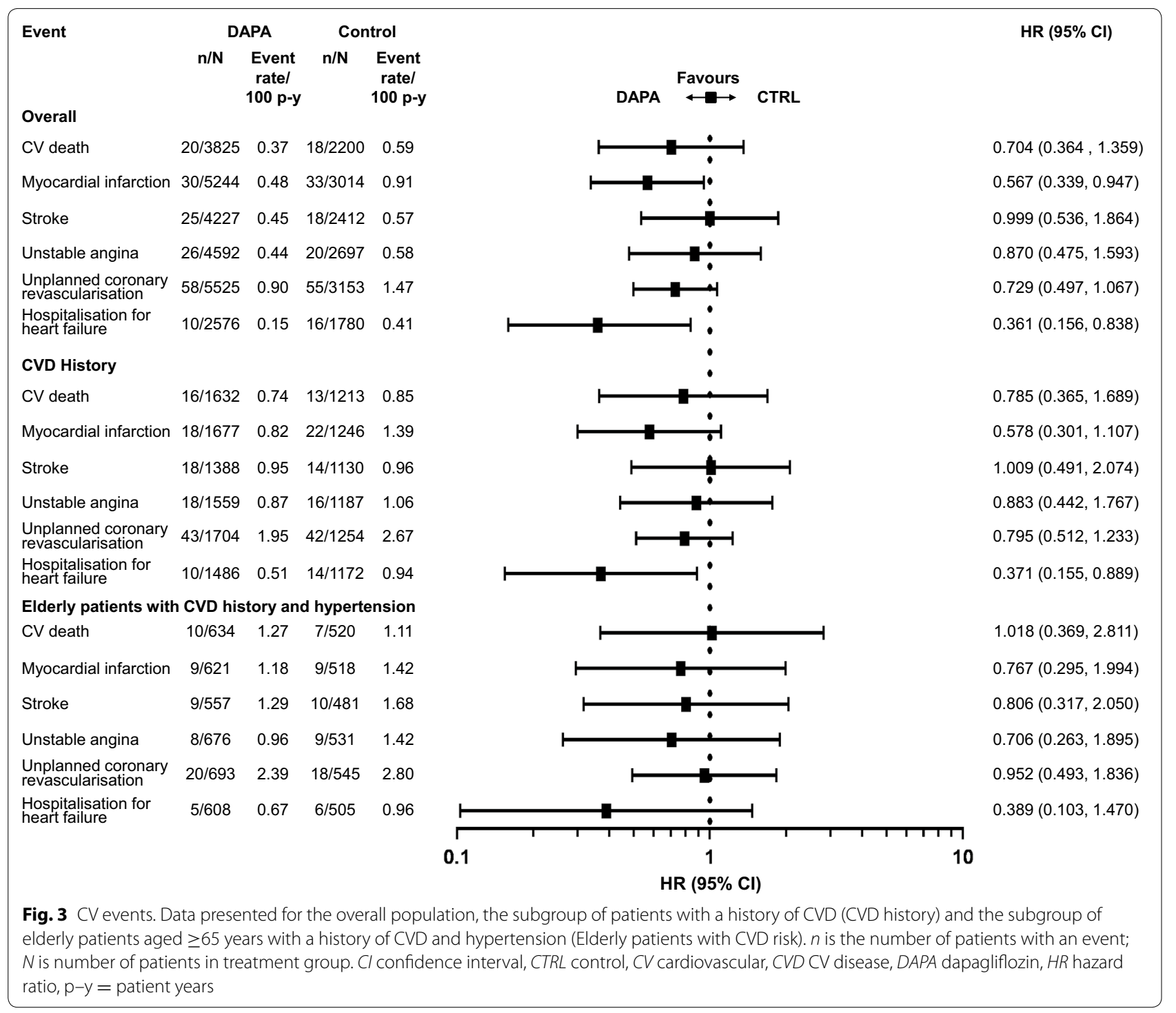

of obesity and T2DM indicates that empagliflozin may improve $\mathrm{CV}$ injury and remodelling, vascular dysfunction, and cognitive decline [66]; in addition to reducing arterial stiffness in young patients with T1DM [67].

In line with this multifactorial risk factor hypothesis, and results generated from this and other meta-analyses that investigated the effects of SGLT2 inhibitors on CV outcomes, positive results were also recently reported with empagliflozin, in the first CV outcomes study with an SGLT2 inhibitor in patients with T2DM and established CVD [47]. Superiority for the primary outcome of MACE was driven by significantly lower rates of death from CV causes while there was no statistical difference between the treatment groups in rates of MI or stroke. Significantly lower rates of hospitalisation for heart failure and death from any cause were also observed; consistent with the current analysis, which reported beneficial or neutral point estimates for all $\mathrm{CV}$ events with dapagliflozin, including a beneficial estimate on hospitalisation for heart failure. It should be noted that eGFR levels were higher in the current study than the empagliflozin study [47] [baseline eGFR (SD): 83.9 (21.3) and 83.6 (21.1) mL/ $\min / 1.73 \mathrm{~m}^{2}$ with dapagliflozin and control, respectively; vs. $74.2(21.6)$ and $73.8(21.1) \mathrm{mL} / \mathrm{min} / 1.73 \mathrm{~m}^{2}$ with empagliflozin and placebo], which could potentially impact on the overall frequency of CV events.

In the empagliflozin CV outcomes study, the cumulative probability of the primary outcome showed an early separation between the treatment groups [47]. In the current meta-analysis, a gradual separation was seen between the dapagliflozin and control curves, based on 134 MACE events. Variability may play a role in the different patterns 


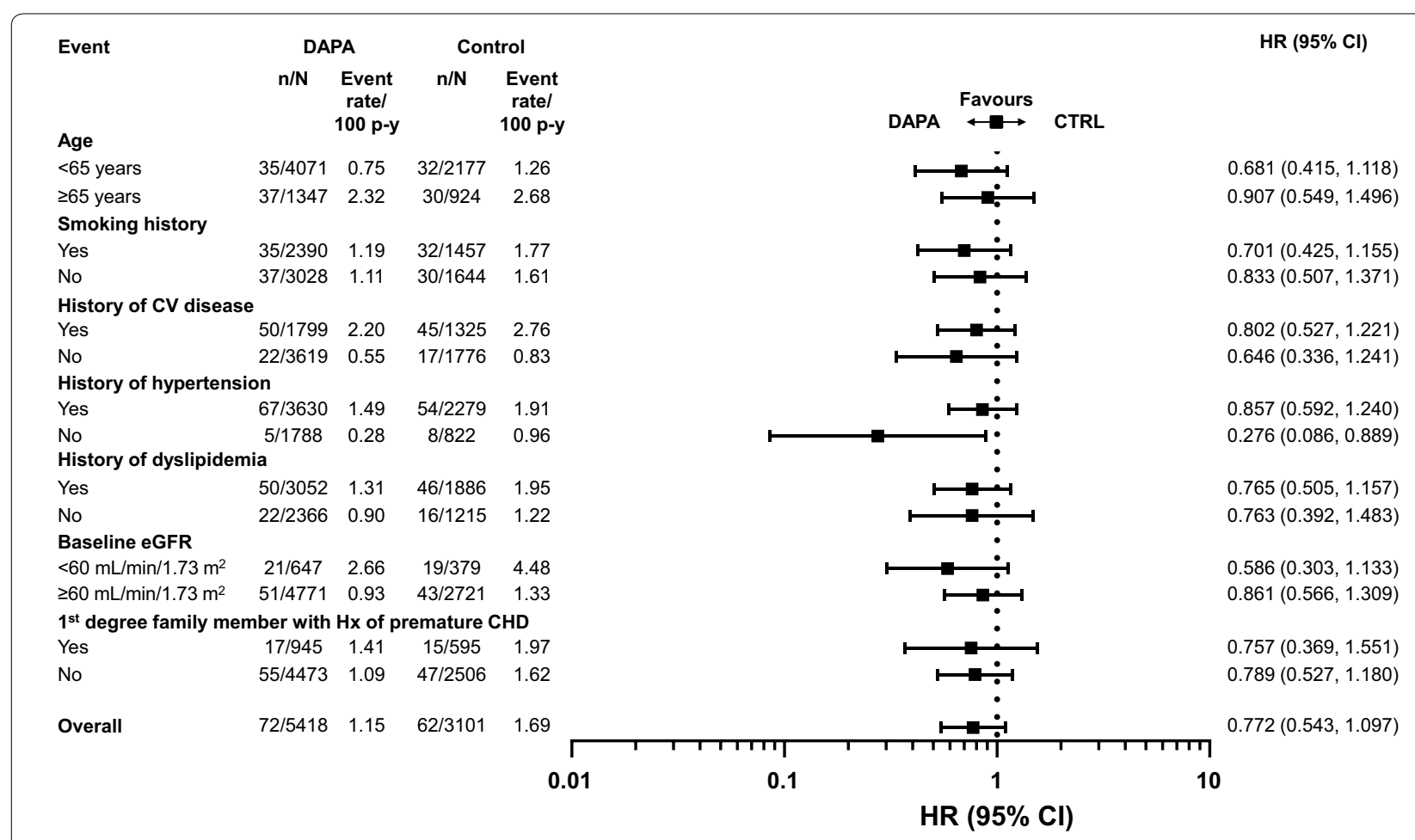

Fig. 4 MACE in the overall population by presence or absence of $C V$ risk factors. $n$ is the number of patients with an event; $N$ is the number of patients in treatment group. CHD coronary heart disease, Cl confidence interval, CV cardiovascular, CTRL control, DAPA dapagliflozin, eGFR estimated glomerular filtration rate, HR hazard ratio, Hx history, MACE major adverse cardiovascular events (CV death, myocardial infarction and stroke),

$\mathrm{p}-\mathrm{y}=$ patient-years

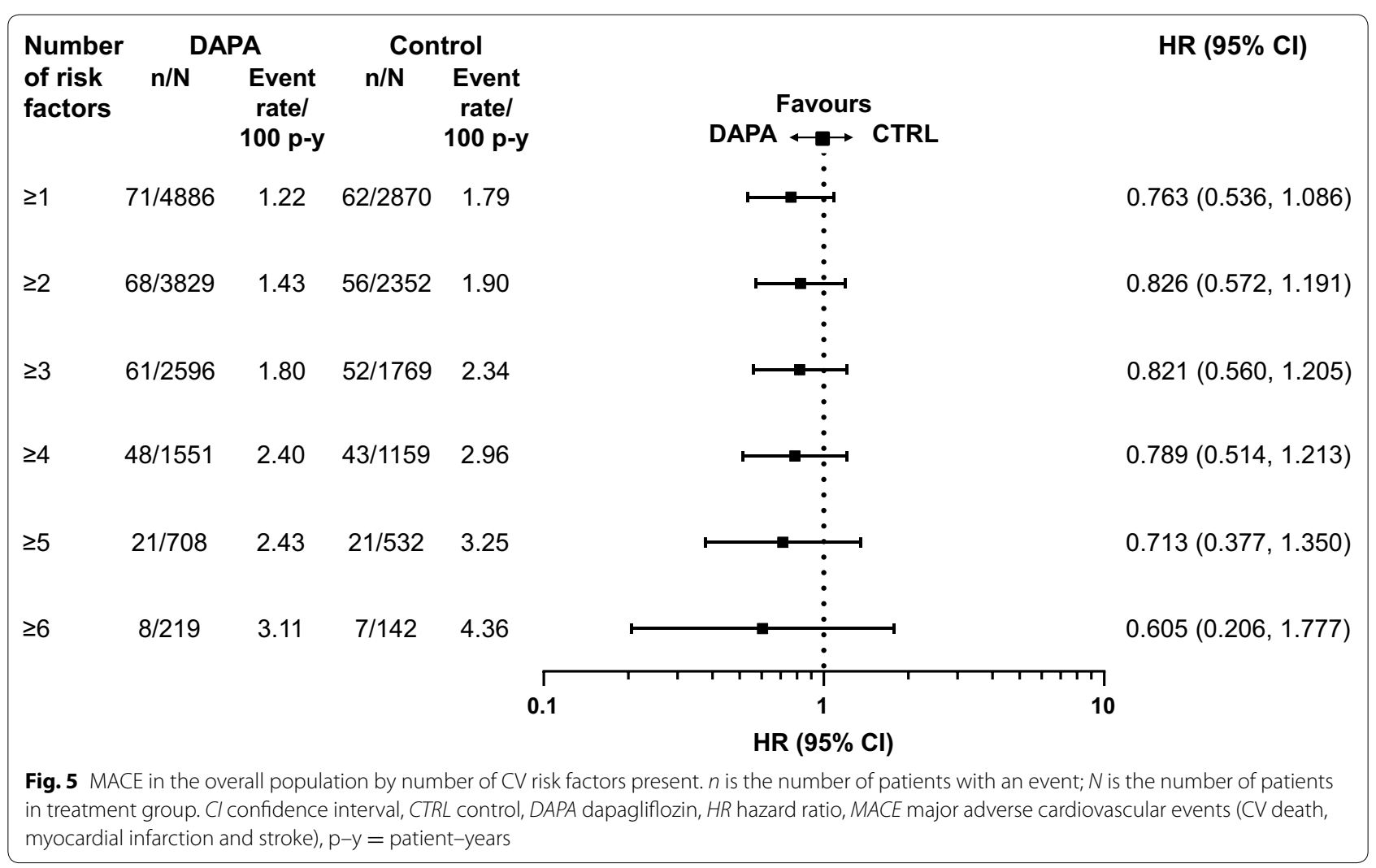




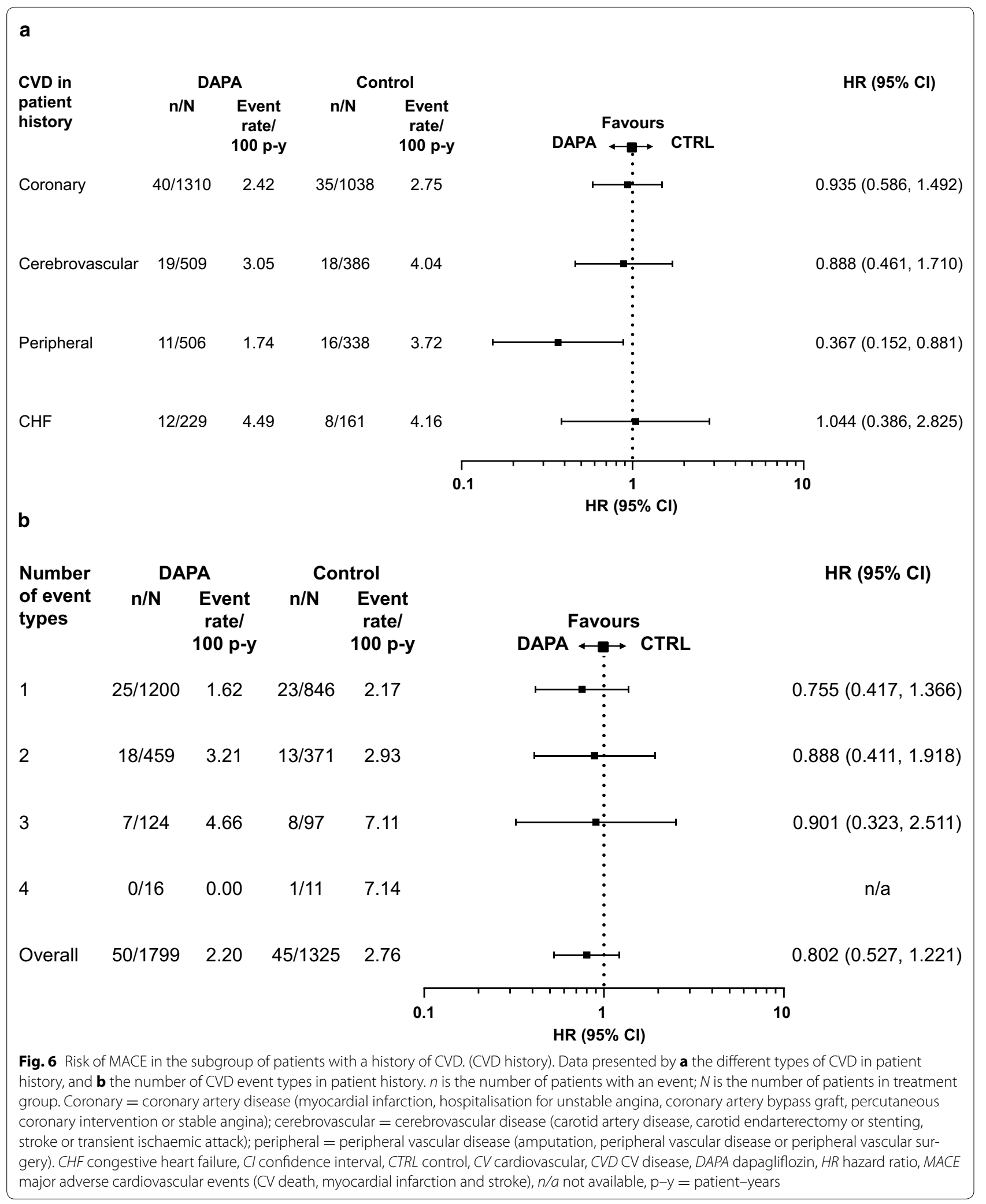




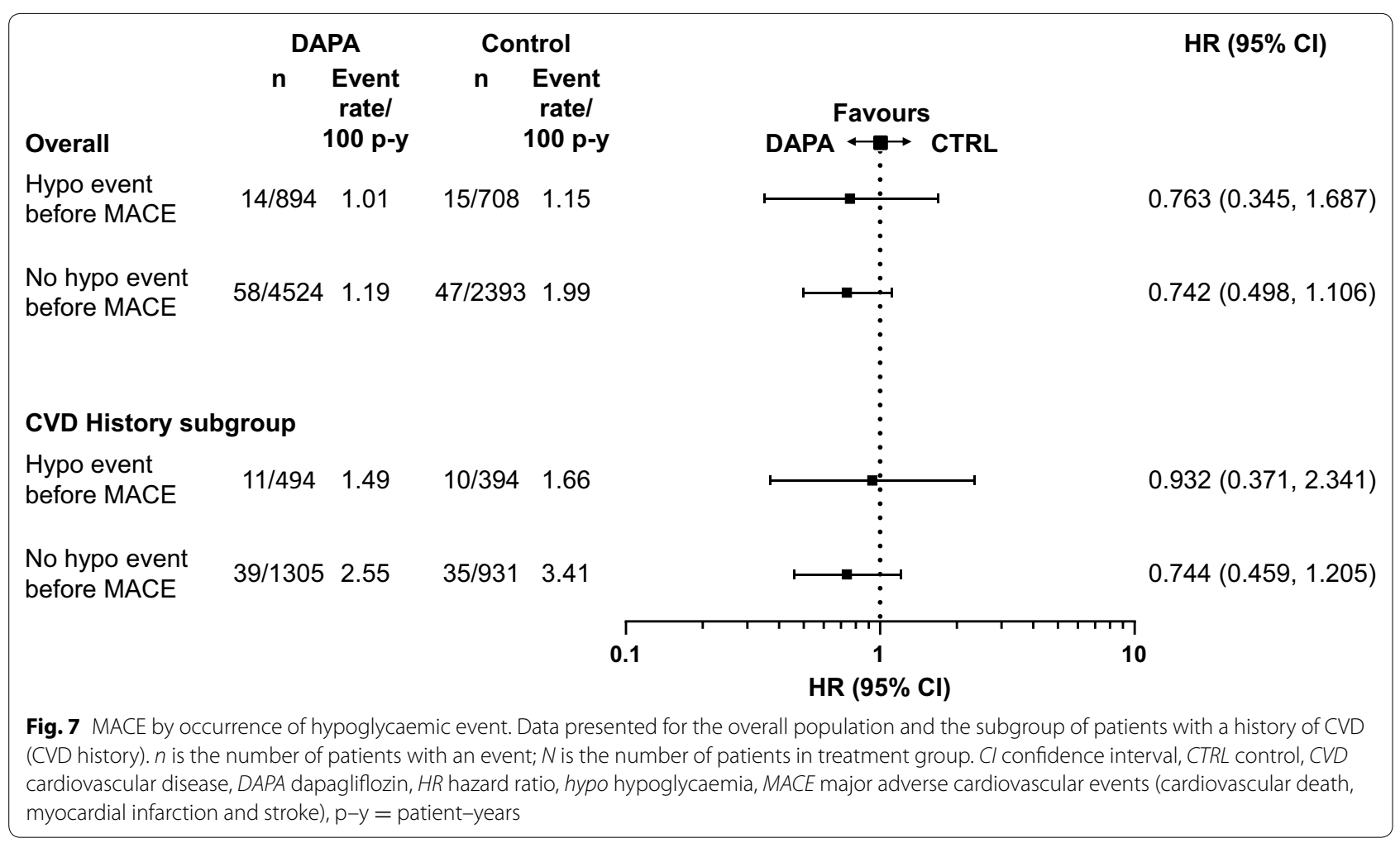

observed in the current analysis and the empagliflozin outcome study, due to substantial differences in study design and population. Dapagliflozin and empagliflozin have similar profiles and no established mechanism suggests a different time to effect. Similar time to effect patterns were observed for dapagliflozin and empagliflozin for hospitalisation for heart failure, although as previously noted this was based on only 26 events in this meta-analysis.

The CV effects of SGLT2 inhibitors calls for further studies and confirmation. The prospective, randomised CV outcomes trial DECLARE TIMI-58 [48], with an estimated enrolment of 17,150 patients and expected median follow-up of more than 4 years, will document the effects of dapagliflozin on $\mathrm{CV}$ outcomes in patients $\geq 40$ years old with T2DM and established CVD or multiple CV risk factors [48]. This study is uniquely positioned by its broader patient population, including both established CVD and multiple risk factor patients, large sample size and long-term follow-up to provide further evidence on the effects of SGLT2 inhibitors on CV risk.

\section{Conclusions}

In this meta-analysis of data from across the dapagliflozin clinical development programme, including high $\mathrm{CV}$ risk patients, there was no evidence for increased risk of major adverse $\mathrm{CV}$ events with dapagliflozin. The results suggest the potential for a beneficial CV effect by dapagliflozin which is consistent with the multifactorial benefits on CV risk factors associated with SGLT2 inhibitors.

\section{Additional file}

Additional file 1: Table S1. Studies included in the meta-analysis.

\section{Abbreviations}

CHF: congestive heart failure; Cl: confidence interval; CV: cardiovascular; CVD: cardiovascular disease; DECLARE TIMI-58: dapagliflozin effect on cardiovascular events TIMI-58; eGFR: estimated glomerular filtration rate; EMA: European Medicines Agency; FDA: US Food and Drug Administration; HR: hazard ratio; LDL: low-density lipoprotein; MACE: major adverse cardiovascular events; MACE+UA: major adverse cardiovascular events + hospitalisation for unstable angina; MedDRA: Medical Dictionary for Regulatory Activities; MI: myocardial infarction; SGLT2: sodium-glucose cotransporter 2; T2DM: type 2 diabetes mellitus; UA: unstable angina; US: United States.

\section{Authors' contributions}

All authors contributed to the design of the meta-analysis, the analysis and interpretation of the data and the drafting and critical revision of the manuscript. All authors read and approved the final manuscript.

\section{Acknowledgements}

The authors would like to thank Robert Frederich, Anna Maria Langkilde, James F. List and Agata Ptaszynska for contributions to data analysis and interpretation. This analysis was funded by AstraZeneca. Editorial assistance was provided by Mark Davies of in Science Communications, Springer Healthcare Ltd, and funding support was provided by AstraZeneca. 


\section{Competing interests}

Christian Sonesson, Ingrid Gause-Nilsson, Eva Johnsson, and Peter A. Johansson are employees and stock/shareholders of AstraZeneca.

Received: 19 November 2015 Accepted: 10 February 2016 Published online: 19 February 2016

\section{References}

1. Emerging Risk Factors Collaboration, Seshasai SR, Kaptoge $S$, Thompson A, Di Angelantonio E, Gao P, Sarwar N, Whincup PH, Mukamal KJ, Gillum $R F$, et al. Diabetes mellitus, fasting glucose, and risk of cause-specific death. N Engl J Med. 2011;364(9):829-41.

2. American Diabetes Association. (8) Cardiovascular disease and risk management. Diabetes Care. 2015;38(Suppl):S49-57.

3. Gregg EW, Li Y, Wang J, Burrows NR, Ali MK, Rolka D, Williams DE, Geiss L. Changes in diabetes-related complications in the United States, 1990-2010. N Engl J Med. 2014;370(16):1514-23.

4. O'Keefe JH, Abuannadi M, Lavie CJ, Bell DS. Strategies for optimizing glycemic control and cardiovascular prognosis in patients with type 2 diabetes mellitus. Mayo Clin Proc. 2011;86(2):128-38.

5. Elley CR, Kenealy T, Robinson E, Drury PL. Glycated haemoglobin and cardiovascular outcomes in people with Type 2 diabetes: a large prospective cohort study. Diabet Med. 2008;25(11):1295-301.

6. Khaw KT, Wareham N, Bingham S, Luben R, Welch A, Day N. Association of hemoglobin A1C with cardiovascular disease and mortality in adults: the European prospective investigation into cancer in Norfolk. Ann Intern Med. 2004;141(6):413-20.

7. Holman RR, Sourij H, Califf RM. Cardiovascular outcome trials of glucose-lowering drugs or strategies in type 2 diabetes. Lancet. 2014;383(9933):2008-17.

8. Gerstein HC, Miller ME, Byington RP, Goff DC Jr, Bigger JT, Buse JB, Cushman WC, Genuth S, Ismail-Beigi F, Grimm RH Jr, et al. Effects of intensive glucose lowering in type 2 diabetes. N Engl J Med. 2008;358(24):2545-59.

9. Patel A, MacMahon S, Chalmers J, Neal B, Billot L, Woodward M, Marre M, Cooper M, Glasziou P, Grobbee D, et al. Intensive blood glucose control and vascular outcomes in patients with type 2 diabetes. N Engl J Med. 2008;358(24):2560-72.

10. Duckworth W, Abraira C, Moritz T, Reda D, Emanuele N, Reaven PD, Zieve FJ, Marks J, Davis SN, Hayward R, et al. Glucose control and vascular complications in veterans with type 2 diabetes. N Engl J Med. 2009;360(2):129-39.

11. Mannucci E, Monami M, Lamanna C, Gori F, Marchionni N. Prevention of cardiovascular disease through glycemic control in type 2 diabetes: a meta-analysis of randomized clinical trials. Nutr Metab Cardiovasc Dis. 2009;19(9):604-12.

12. Boussageon R, Bejan-Angoulvant T, Saadatian-Elahi M, Lafont S, Bergeonneau C, Kassai B, Erpeldinger S, Wright JM, Gueyffier F, Cornu C. Effect of intensive glucose lowering treatment on all cause mortality, cardiovascular death, and microvascular events in type 2 diabetes: meta-analysis of randomised controlled trials. BMJ. 2011;343:d4169.

13. Raz I, Riddle MC, Rosenstock J, Buse JB, Inzucchi SE, Home PD, Del Prato S, Ferrannini E, Chan JC, Leiter LA, et al. Personalized management of hyperglycemia in type 2 diabetes: reflections from a Diabetes Care Editors'Expert Forum. Diabetes Care. 2013;36(6):1779-88.

14. Inzucchi SE, Bergenstal RM, Buse JB, Diamant M, Ferrannini E, Nauck M, Peters AL, Tsapas A, Wender R, Matthews DR. Management of hyperglycemia in type 2 diabetes: a patient-centered approach: position statement of the American Diabetes Association (ADA) and the European Association for the Study of Diabetes (EASD). Diabetes Care. 2012;35(6):1364-79.

15. Inzucchi SE, Bergenstal RM, Buse JB, Diamant M, Ferrannini E, Nauck M, Peters AL, Tsapas A, Wender R, Matthews DR. Management of hyperglycemia in type 2 diabetes, 2015: a patient-centered approach: update to a position statement of the American Diabetes Association and the European Association for the Study of Diabetes. Diabetes Care. 2015;38(1):140-9.

16. Shi L, Ye X, Lu M, Wu EQ, Sharma H, Thomason D, Fonseca VA. Clinical and economic benefits associated with the achievement of both $\mathrm{HbA} 1 \mathrm{c}$ and
LDL cholesterol goals in veterans with type 2 diabetes. Diabetes Care. 2013:36(10):3297-304.

17. Stark Casagrande S, Fradkin JE, Saydah SH, Rust KF, Cowie CC. The prevalence of meeting $\mathrm{A} 1 \mathrm{C}$, blood pressure, and LDL goals among people with diabetes, 1988-2010. Diabetes Care. 2013;36(8):2271-9.

18. AstraZeneca UK Limited. SPC: Forxiga $5 \mathrm{mg} \& 10 \mathrm{mg}$ film coated tablets. 2015. http://www.medicines.org.uk/EMC/medicine/27188. Accessed 30 Oct 2015.

19. List JF, Woo V, Morales E, Tang W, Fiedorek FT. Sodium-glucose cotransport inhibition with dapagliflozin in type 2 diabetes. Diabetes Care. 2009;32(4):650-7.

20. Wilding JP, Norwood P, T'Joen C, Bastien A, List JF, Fiedorek FT. A study of dapagliflozin in patients with type 2 diabetes receiving high doses of insulin plus insulin sensitizers: applicability of a novel insulin-independent treatment. Diabetes Care. 2009;32(9):1656-62.

21. Bailey CJ, Gross JL, Pieters A, Bastien A, List JF. Effect of dapagliflozin in patients with type 2 diabetes who have inadequate glycaemic control with metformin: a randomised, double-blind, placebo-controlled trial. Lancet. 2010;375(9733):2223-33.

22. Henry RR, Murray AV, Marmolejo MH, Hennicken D, Ptaszynska A, List JF. Dapagliflozin, metformin XR, or both: initial pharmacotherapy for type 2 diabetes, a randomised controlled trial. Int J Clin Pract. 2012;66(5):446-56.

23. Nauck MA, Del Prato S, Meier JJ, Duran-Garcia S, Rohwedder K, Elze M, Parikh SJ. Dapagliflozin versus glipizide as add-on therapy in patients with type 2 diabetes who have inadequate glycemic control with metformin: a randomized, 52-week, double-blind, active-controlled noninferiority trial. Diabetes Care. 2011;34(9):2015-22.

24. Strojek K, Yoon KH, Hruba V, Elze M, Langkilde AM, Parikh S. Effect of dapagliflozin in patients with type 2 diabetes who have inadequate glycaemic control with glimepiride: a randomized, 24-week, double-blind, placebocontrolled trial. Diabetes Obes Metab. 2011;13(10):928-38.

25. Kohan DE, Fioretto P, Tang W, List JF. Long-term study of patients with type 2 diabetes and moderate renal impairment shows that dapagliflozin reduces weight and blood pressure but does not improve glycemic control. Kidney Int. 2014;85(4):962-71.

26. Rosenstock J, Vico M, Wei L, Salsali A, List JF. Effects of dapagliflozin, an SGLT2 inhibitor, on $\mathrm{HbA}(1 \mathrm{c})$, body weight, and hypoglycemia risk in patients with type 2 diabetes inadequately controlled on pioglitazone monotherapy. Diabetes Care. 2012;35(7):1473-8.

27. Wilding JP, Woo V, Rohwedder K, Sugg J, Parikh S. Dapagliflozin in patients with type 2 diabetes receiving high doses of insulin: efficacy and safety over 2 years. Diabetes Obes Metab. 2014;16(2):124-36.

28. Bolinder J, Ljunggren O, Johansson L, Wilding J, Langkilde AM, Sjostrom CD, Sugg J, Parikh S. Dapagliflozin maintains glycaemic control while reducing weight and body fat mass over 2 years in patients with type 2 diabetes mellitus inadequately controlled on metformin. Diabetes Obes Metab. 2014;16(2):159-69.

29. Jabbour SA, Hardy E, Sugg J, Parikh S. Dapagliflozin is effective as add-on therapy to sitagliptin with or without metformin: a 24-week, multicenter, randomized, double-blind, placebo-controlled study. Diabetes Care. 2014;37(3):740-50.

30. Cefalu WT, Leiter LA, de Bruin TW, Gause-Nilsson I, Sugg J, Parikh SJ. Dapagliflozin's effects on glycemia and cardiovascular risk factors in highrisk patients with type 2 diabetes: a 24-week, multicenter, randomized, double-blind, placebo-controlled study with a 28-week extension. Diabetes Care. 2015;38(7):1218-27.

31. Leiter LA, Cefalu WT, de Bruin TW, Gause-Nilsson I, Sugg J, Parikh SJ. Dapagliflozin added to usual care in individuals with type 2 diabetes mellitus with preexisting cardiovascular disease: a 24-week, multicenter, randomized, double-blind, placebo-controlled study with a 28-week extension. J Am Geriatr Soc. 2014;62(7):1252-62.

32. Kaku K, Kiyosue A, Inoue S, Ueda N, Tokudome T, Yang J, Langkilde AM. Efficacy and safety of dapagliflozin monotherapy in Japanese patients with type 2 diabetes inadequately controlled by diet and exercise. Diabetes Obes Metab. 2014;16(11):1102-10.

33. Ferrannini E, Ramos SJ, Salsali A, Tang W, List JF. Dapagliflozin monotherapy in type 2 diabetic patients with inadequate glycemic control by diet and exercise: a randomized, double-blind, placebo-controlled, phase 3 trial. Diabetes Care. 2010;33(10):2217-24. 
34. Bailey CJ, lqbal N, T'Joen C, List JF. Dapagliflozin monotherapy in drugnaive patients with diabetes: a randomized-controlled trial of low-dose range. Diabetes Obes Metab. 2012;14(10):951-9.

35. Lambers Heerspink HJ, de Zeeuw D, Wie L, Leslie B, List J. Dapagliflozin a glucose-regulating drug with diuretic properties in subjects with type 2 diabetes. Diabetes Obes Metab. 2013;15(9):853-62.

36. Mudaliar S, Henry RR, Boden G, Smith S, Chalamandaris AG, Duchesne D, Iqbal N, List J. Changes in insulin sensitivity and insulin secretion with the sodium glucose cotransporter 2 inhibitor dapagliflozin. Diabetes Technol Ther. 2014;16(3):137-44

37. Ji L, Ma J, Li H, Mansfield TA, T'Joen CL, lqbal N, Ptaszynska A, List JF. Dapagliflozin as monotherapy in drug-naive Asian patients with type 2 diabetes mellitus: a randomized, blinded, prospective phase III study. Clin Ther. 2014;36(1):84-100

38. Kaku K, Inoue S, Matsuoka O, Kiyosue A, Azuma H, Hayashi N, Tokudome T, Langkilde AM, Parikh S. Efficacy and safety of dapagliflozin as a monotherapy for type 2 diabetes mellitus in Japanese patients with inadequate glycaemic control: a phase II multicentre, randomized, double-blind, placebo-controlled trial. Diabetes Obes Metab. 2013;15(5):432-40.

39. Zhang M, Zhang L, Wu B, Song H, An Z, Li S. Dapagliflozin treatment for type 2 diabetes: a systematic review and meta-analysis of randomized controlled trials. Diabetes Metab Res Rev. 2014;30(3):204-21.

40. Inzucchi SE, Zinman B, Wanner C, Ferrari R, Fitchett D, Hantel S, Espadero RM, Woerle HJ, Broedl UC, Johansen OE. SGLT-2 inhibitors and cardiovascular risk: proposed pathways and review of ongoing outcome trials. Diab Vasc Dis Res. 2015;12(2):90-100.

41. Center for Drug Evaluation and Research (CDER). Guidance for industry: diabetes mellitus - evaluating cardiovascular risk in new antidiabetic therapies to treat type 2 diabetes. 2008. http://www.fda.gov/downloads/Drugs/GuidanceComplianceRegulatorylnformation/Guidances/ ucm071627.pdf. Accessed 30 Oct 2015.

42. European Medicines Agency. Guideline on clinical investigation of medicinal products in the treatment or prevention of diabetes mellitus. 2012. http://www.ema.europa.eu/docs/en_GB/document_library/Scientific guideline/2012/06/WC500129256.pdf. Accessed 30 Oct 2015

43. Scirica BM, Bhatt DL, Braunwald E, Steg PG, Davidson J, Hirshberg B, Ohman P, Frederich R, Wiviott SD, Hoffman EB, et al. Saxagliptin and cardiovascular outcomes in patients with type 2 diabetes mellitus. N Engl J Med. 2013;369(14):1317-26.

44. White WB, Cannon CP, Heller SR, Nissen SE, Bergenstal RM, Bakris GL, Perez AT, Fleck PR, Mehta CR, Kupfer S, et al. Alogliptin after acute coronary syndrome in patients with type 2 diabetes. N Engl J Med. 2013;369(14):1327-35.

45. Green JB, Bethel MA, Armstrong PW, Buse JB, Engel SS, Garg J, Josse R, Kaufman KD, Koglin J, Korn S et al. Effect of sitagliptin on cardiovascular outcomes in type 2 diabetes. N Engl J Med. 2015;373(3):232-42.

46. Riddle MC. The evaluation of lixisenatide in acute coronary syndromethe results of ELIXA. Presented at the 75th Scientific Sessions of the American Diabetes Association June 5-9, 2015, Boston, MA; 2015.

47. Zinman B, Wanner C, Lachin JM, Fitchett D, Bluhmki E, Hantel S, Mattheus $M$, Devins T, Johansen OE, Woerle HJ, et al. Empagliflozin, cardiovascular outcomes, and mortality in type 2 diabetes. N Engl J Med. 2015; doi:10.1056/NEJMoa1504720.

48. Clinicaltrials.gov. Multicenter trial to evaluate the effect of dapagliflozin on the incidence of cardiovascular events (DECLARE-TIMI58). https://clinicaltrials.gov/ct2/show/NCT01730534. Accessed 08 Jan 2016.

49. Marso SP, Poulter NR, Nissen SE, Nauck MA, Zinman B, Daniels GH, Pocock S, Steinberg WM, Bergenstal RM, Mann JF, et al. Design of the liraglutide effect and action in diabetes: evaluation of cardiovascular outcome results (LEADER) trial. Am Heart J. 2013;166(5):823-30.

50. Neal B, Perkovic V, de Zeeuw D, Mahaffey KW, Fulcher G, Stein P, Desai M, Shaw W, Jiang J, Vercruysse F, et al. Rationale, design, and baseline characteristics of the Canagliflozin Cardiovascular Assessment Study (CANVAS) — a randomized placebo-controlled trial. Am Heart J. 2013;166(2):217-23.
51. Langkilde AM, Johansson P, Ptaszynska A, Johnsson E. Abstract 11105 : cardiovascular safety of the SGLT2 inhibitor dapagliflozin: meta-analysis with $>6000$ patient-years exposure. Presented at the American Heart Association 2013 Scientific Sessions, Dallas, TX, November 16-20, 2013; 2013.

52. Lin CC, Li Cl, Yang SY, Liu CS, Chen CC, Fuh MM, Chen W, Li TC. Variation of fasting plasma glucose: a predictor of mortality in patients with type 2 diabetes. Am J Med. 2012;125(4):416e9-18.

53. Ceriello A, Kilpatrick ES. Glycemic variability: both sides of the story. Diabetes Care. 2013;36(Suppl 2):S272-5.

54. Standl E, Schnell O, Ceriello A. Postprandial hyperglycemia and glycemic variability: should we care? Diabetes Care. 2011;34(Suppl 2):S120-7.

55. Bonds DE, Miller ME, Bergenstal RM, Buse JB, Byington RP, Cutler JA, Dudl RJ, Ismail-Beigi F, Kimel AR, Hoogwerf B, et al. The association between symptomatic, severe hypoglycaemia and mortality in type 2 diabetes: retrospective epidemiological analysis of the ACCORD study. BMJ. 2010:340:b4909.

56. Zoungas S, Patel A, Chalmers J, de Galan BE, Li Q, Billot L, Woodward M, Ninomiya T, Neal B, MacMahon S, et al. Severe hypoglycemia and risks of vascular events and death. N Engl J Med. 2010;363(15):1410-8.

57. Mellbin LG, Ryden L, Riddle MC, Probstfield J, Rosenstock J, Diaz R, Yusuf $\mathrm{S}$, Gerstein HC. Does hypoglycaemia increase the risk of cardiovascular events? A report from the ORIGIN trial. Eur Heart J. 2013;34(40):3137-44.

58. Goto A, Arah OA, Goto M, Terauchi Y, Noda M. Severe hypoglycaemia and cardiovascular disease: systematic review and meta-analysis with bias analysis. BMJ. 2013;347:f4533.

59. Vasilakou D, Karagiannis T, Athanasiadou E, Mainou M, Liakos A, Bekiari E, Sarigianni M, Matthews DR, Tsapas A. Sodium-glucose cotransporter 2 inhibitors for type 2 diabetes: a systematic review and meta-analysis. Ann Intern Med. 2013;159(4):262-74.

60. Hirshberg B, Katz A. Cardiovascular outcome studies with novel antidiabetes agents: scientific and operational considerations. Diabetes Care. 2013:36(Suppl 2):S253-8.

61. Fioretto P, Giaccari A, Sesti G. Efficacy and safety of dapagliflozin, a sodium glucose cotransporter 2 (SGLT2) inhibitor, in diabetes mellitus. Cardiovasc Diabetol. 2015;14:142.

62. Weber MA, Mansfield TA, Cain VA, lqbal N, Parikh S, Ptaszynska A. Blood pressure and glycaemic effects of dapagliflozin versus placebo in patients with type 2 diabetes on combination antihypertensive therapy: a randomised, double-blind, placebo-controlled, phase 3 study. Lancet Diabetes Endocrinol. 2015. doi:10.1016/S2213-8587(15)00417-9.

63. Weber MA, Mansfield TA, Alessi F, labal N, Parikh S, Ptaszynska A. Effects of dapagliflozin on blood pressure in hypertensive diabetic patients on renin-angiotensin system blockade. Blood Press. 2016;25(2):93-103. doi:1 0.3109/08037051.2015.1116258.

64. Fioretto P, Stefansson BV, Johnsson EKA, Cain VA, Sjostrom D. Dapagliflozin reduces albuminuria over 2 years in diabetic patients with renal impairment. J Am Soc Nephrol. 2015;26:1A. Abstr. TH-OR001.

65. Lambers-Heerspink H, Johnsson E, Gause-Nilsson I, Johansson K, Sjostrom CD. Dapagliflozin reduces albuminuria on top of renin-angiotensin system blockade in hypertensive diabetic patients. Diabetes. 2015;64(Suppl 1):A303. Abstr. 1176-P.

66. Lin B, Koibuchi N, Hasegawa Y, Sueta D, Toyama K, Uekawa K, Ma M, Nakagawa T, Kusaka H, Kim-Mitsuyama S. Glycemic control with empagliflozin, a novel selective SGLT2 inhibitor, ameliorates cardiovascular injury and cognitive dysfunction in obese and type 2 diabetic mice. Cardiovasc Diabetol. 2014;13:148

67. Cherney DZ, Perkins BA, Soleymanlou N, Har R, Fagan N, Johansen OE, Woerle HJ, von Eynatten M, Broedl UC. The effect of empagliflozin on arterial stiffness and heart rate variability in subjects with uncomplicated type 1 diabetes mellitus. Cardiovasc Diabetol. 2014;13:28. 